\title{
Alfabetização de estudante com deficiência intelectual: uso de um software educativo
}

\author{
Literacy of a student with intellectual disabilities: use of educational software
}

Alfabetización de estudiante con discapacidad intelectual: uso de un software educativo

Jaquelini Grillo Biral Rocha1*, Edmar Reis Thiengo².

\begin{abstract}
RESUMO
Objetivo: Discutir o processo de alfabetização de um aluno com deficiência intelectual a partir do uso do software educacional Coelho Sabido. Método: Trata-se estudo de caso, de caráter qualitativo realizado com um aluno com deficiência intelectual após aprovação do Comitê de Ética e Pesquisa (CEP) do Instituto Vale do Cricaré sob o Parecer Consubstanciado n. 2.899.912. Utilizou-se a observação livre e os registros em Diário de Bordo. Optou-se por assumir como aporte os pressupostos teóricos de Vygotsky e seus mecanismos de compensação, bem como entender o processo de desenvolvimento e aprendizagem a partir da conceituação das Zonas de desenvolvimento proximal, destacando a importância da mediação. Resultados: Foram organizados a partir das observações sobre a interação estabelecida pelo sujeito da pesquisa com o software Coelho sabido: "Parque de diversões", nos atendimentos em sala de recurso multifuncionais. Conclusão: Os recursos tecnológicos desempenharam um grande potencial mediador e lúdico para o aprimoramento e desenvolvimento de habilidades fundamentais ao processo de alfabetização a contar com a mediação sistemática do professor.
\end{abstract}

Palavras-chave: Alfabetização, Deficiência intelectual, Software educacional, Atendimento educacional especializado.

\begin{abstract}
Objective: To discuss the literacy process of a student with intellectual disability using the Coelho Sabido educational software. Method: A qualitative case study carried out with a student with intellectual disability after approval by the Ethics and Research Committee (CEP) of the Vale do Cricaré Institute, under Supported Opinion no. 2,899,912. It was used the free observation and the records in Logbook. Vygotsky's theoretical assumptions and compensation mechanisms were chosen as well as to understand the process of development and learning from the conception of the Zones of proximal development, highlighting the importance of mediation. Results: They were organized from the observations about the interaction established by the subject of the research with the educational software Coelho known "Amusement park", during the attendances in multifunctional resource room. Conclusion: The technological resources played a great mediating and playful potential for the improvement and development of skills, fundamental to the literacy process, with the systematic mediation of the teacher.
\end{abstract}

Keywords: Literacy, Intellectual disability, Educational software, Specialized educational service.

${ }^{1}$ Faculdade Vale do Cricaré - São Mateus - ES, Centro Estadual Integrado de Educação Rural de Vila Pavão -ES - CEIER. *E-mail: kelybiral@hotmail.com

2Universidade Federal do Espírito Santo. Faculdade Vale do Cricaré - São Mateus-ES.

SUBMETIDO EM: 3/2019

ACEITO EM: 4/2019

PUBLICADO EM: 6/2019

REAS/EJCH | Vol. 11 (11) | e513 | DOI: https://doi.org/10.25248/reas.e513.2019 Página 1 de 8 


\section{RESUMEN}

Objetivo: Discutir el proceso de alfabetización de un alumno con discapacidad intelectual a partir del uso del software educativo Conejo Sabido. Método: Un estudio de caso, de carácter cualitativo realizado con un alumno con discapacidad intelectual tras la aprobación del Comité de Ética e Investigación (CEP) del Instituto Vale do Cricaré bajo el Dictamen Consubstanciado n. 2.899.912. Se utilizó la observación libre y los registros en Diario de Bordo. Se optó por asumir como aporte los presupuestos teóricos de Vygotsky y sus mecanismos de compensación, así como entender el proceso de desarrollo y aprendizaje a partir de la concepción de las Zonas de desarrollo proximal, destacando la importancia de la mediación. Resultados: Se organizaron a partir de las observaciones sobre la interacción establecida por el sujeto de la investigación con el software educativo Coelho conocido "Parque de diversiones", durante las llamadas en sala de recursos multifuncionales. Conclusión: Los recursos tecnológicos desempeñaron un gran potencial mediador y lúdico para el perfeccionamiento y desarrollo de habilidades fundamentales al proceso de alfabetización a contar con la mediación sistemática del profesor.

Palabras clave: Alfabetización, Deficiencia intelectual, Software educativo, Atención educativa especializada.

\section{INTRODUÇÃO}

As conceituações, terminologias e abordagens sobre a deficiência intelectual têm passado por frequentes mudanças direcionadas por estudos e pesquisas em diferentes áreas. $O$ contexto e as concepções de sociedade presentes em cada momento da história influenciaram diretamente na forma de ver estes sujeitos, enraizados às ideologias religiosas, políticas e sociais. Registros apontam momentos de abandono, extermínio, superproteção, segregação e integração, ambas alicerçadas em concepções e paradigmas carregados de estimas e preconceitos (SILVA OM, 2009).

Com o passar dos tempos vários movimentos de caráter político e educacional em defesa das pessoas com deficiência ganharam força mundialmente. A partir do século XX, avanços importantes foram alcançados, porém muitas mudanças ainda teriam que acontecer considerando os rumos que tomou a inclusão excludente (ALENCAR GAR et al., 2010).

Falar em inclusão escolar é pensar em uma educação inovadora pautada em um fazer diferenciado livre de preconceitos e discriminação. Sabe-se que tal empreitada requer de todos os envolvidos, mudança de concepções e paradigmas que por muito tempo perpetuaram dentro de nossas escolas, famílias e sociedade (MANTOAN MTE, 2003)

Repensar uma escola para os dias atuais tem sido um dos grandes desafios enfrentados pelos profissionais da educação, em um contexto que a diversidade e a diferença não podem ser desconsideradas. Diante desta realidade torna-se necessário e urgente buscarmos pela ressignificação das práticas pedagógicas destinadas aos alunos com deficiência Intelectual, que atendam suas necessidades e singularidades, rompendo com modelos de atividades mecânicas e repetitivas.

Neste cenário de mudanças e transformações, as Tecnologias de Informação e Comunicação (TIC) quando utilizadas de acordo com a realidade do educando, tornam-se instrumentos que despertam o interesse para as novas aprendizagens. Fazendo a transposição para a sala de recursos é a priori que o professor especializado adquira competências que o possibilite programar recursos inovadores que atendam a singularidade de seus alunos (SANCHO JM, 2001; VOLTOLINI R, 2007).

A atual investigação se destina a pensar estratégias que possibilitem a verificação e aprimoramento de habilidade e o desenvolvimento de novas potencialidades em alunos com deficiência intelectual a partir da utilização de recursos tecnológicos. A pesquisa centrou-se na utilização do software Coelho Sabido como estratégia metodológica a ser aplicada a um aluno com deficiência intelectual, no intuito de compreender como os jogos utilizados para ensinar e aprender de forma lúdica, poderão influenciar no desenvolvimento de competências fundamentais ao processo de alfabetização. 


\section{MÉTODOS}

Trata-se de um estudo de caso, de caráter qualitativo, realizado com um aluno com deficiência Intelectual, matriculado no ensino Médio do Centro Estadual Integrado de Educação Rural - CEIER de Vila Pavão- ES, frequentando o AEE - Atendimento Educacional Especializado na própria escola.

O sujeito da pesquisa ainda não domina o traçado e reconhecimento de letras e números em diferentes contextos considerando aspectos como posição, comparação e ordenação. Compreende comandos com facilidade, realiza exercícios de pintura, recorte e colagem necessitando de mediação sistemática em consequência das dificuldades enfrentadas no campo da atenção e concentração.

Apresenta dificuldades nas atividades que envolva memória visual, para a compreensão das relações de igualdade e diferença. Apresenta tônus muscular da mão direita comprometida, dificultando a realização de atividades simples como abotoar a roupa, calçar um tênis, dentre outras, em que são exigidas habilidades ligadas á motricidade fina.

A pesquisa utilizando o Software educacional foi aplicada mediante a constatação do interesse do aluno por recursos tecnológicos ao utilizar computador. Os dados foram coletados na sala de recursos multifuncionais da própria instituição durante os Atendimentos Educacionais Especializados por meio de observação livre e registros em Diário de Bordo a partir da interação do aluno com os espaços disponíveis no software.

Optou-se por assumir como aporte os pressupostos teóricos de Vygotsky e seus mecanismos de compensação, bem como entender o processo de desenvolvimento e aprendizagem a partir da conceituação das Zonas de desenvolvimento proximal, destacando a importância da mediação.

Após aprovação do Comitê de Ética e Pesquisa (CEP) do Instituto Vale do Cricaré com o Parecer Consubstanciado n. 2.899.912; Assinatura do Termo de Consentimento Livre e Esclarecido pelo responsável pelo menor e da Carta de Autorização para Realização da Pesquisa na Instituição assinado pelo gestor da instituição, deu-se início a coleta de dados. O estudo respeitou as exigências formais contidas nas normas nacionais e internacionais regulamentadoras de pesquisa envolvendo seres humanos.

\section{DISCUSSÃO}

As políticas de inclusão da pessoa com deficiência intelectual percorreram caminhos tortuosos, desenvolvendo-se a passos lentos e inseguros. As pessoas com deficiência mental foram diagnosticadas sob a avaliação das áreas da medicina e da psicologia a partir da análise puramente biológica, deixando de lado as interferências entre sujeito e o contexto social em que está inserido. O diagnóstico a partir deste princípio determinou por longas datas o tratamento a estas pessoas, estando, pois, predestinadas ao insucesso, à incapacidade e ao fracasso para toda a vida (VYGOTSKY LS, 1997).

Em um contexto em que imperava o enfoque clínico terapêutico, surge a ideia de que a pessoa com deficiência tem capacidades e potencialidades que precisam ser compensadas. Uma criança com deficiência consegue superar suas limitações através dos mecanismos compensatórios criados pelos defeitos, e os meios culturais ajustados a real necessidade é o principal caminho para compensar o defeito orgânico (VYGOTSKY LS, 1997).

Neste mesmo cenário, as discussões sobre o processo de desenvolvimento e aprendizagem giravam entorno dos conceitos de "Zonas de desenvolvimento proximal". O primeiro nível de desenvolvimento intitulado de real compreende o conjunto de atividades que a criança consegue resolver sozinha.

O segundo nível chamado de potencial, é formado pelas atividades que a criança não consegue realizar sozinha, mas que está próximo de acontecer, necessitando da mediação de pares mais experientes. Esse intervalo entre o que já está apreendido e o que está para apreender chama de zona de desenvolvimento proximal (VYGOTSKY LS, 2005). 
Sob esta ótica, a aprendizagem é fruto das mediações e interações dos sujeitos com seus pares, revelando-nos a importância de superarmos a ênfase aos processos de maturações biológicas, trazendo para o foco o desenvolvimento das funções mentais superiores: memória, atenção, pensamento, consciência (VYGOTSKY LS, 2005).

Evidencia-se a importância do educador conhecer o estudante e o seu nível de desenvolvimento real e a partir destas análises, proporcionar situações de aprendizagem pensadas não no déficit, mas nas potencialidades, nas suas relações sociais, concepções históricas e culturais, amparadas pela mediação (VYGOTSKY LS, 2005).

A deficiência intelectual traz uma vasta gama de conceitos, interpretações e abordagens que levam a inúmeros questionamentos para o ensino nas escolas comuns e para os encaminhamentos no atendimento educacional especializado (BATISTA CAM, 2007; MANTOAN MTE, 2007).

As diretrizes estabelecidas pela Política de 2008 impulsionaram importantes mudanças a favor da educação inclusiva no Brasil. Em suas entrelinhas traz orientações e apontamentos visando à garantia de acesso ao ensino regular dos alunos com necessidades educacionais especiais em todos os níveis de ensino, bem como a oferta do atendimento educacional especializado a partir de serviços e recursos planejados por professores com formação específica visando atender as diferenças.

A partir do Decreto Presidencial n. 6.571/2008, a união assume o compromisso em oferecer apoio técnico e financeiro para a implantação de atendimento educacional especializado a ser ofertado aos alunos com deficiência ou com transtornos globais do desenvolvimento quanto para aqueles com altas habilidades ou superdotação, que estejam matriculados na rede pública de ensino regular, tanto no âmbito federal quanto no dos estados e municípios.

O Atendimento Educacional especializado, passa a assumir um papel importante para o sucesso da inclusão dos alunos com necessidades educacionais especiais, tendo a função de identificar, elaborar e organizar os recursos pedagógicos e de acessibilidades, considerando as necessidades específicas dos alunos a serem atendidos pela modalidade da educação especial (BRASIL, 2008).

\section{Uso de softwares educativos como recurso na educação especial}

No mundo contemporâneo a tecnologia está presente em todas as áreas, não sendo diferente no contexto educacional, por ser uma ferramenta de grande importância no processo de aprendizagem.

Neste cenário de inovações uma nova práxis docente passa a ser exigida, permeada por saberes disciplinares, curriculares e profissionais contextualizadas e adequadas ao atendimento dos alunos da educação especial.

Dentre estes saberes, destacamos o domínio do uso das tecnologias da informação e da comunicação. Ao professor enquanto ator principal, cabe à função de propor inovadoras metodologias utilizando a tecnologia para efetivar o processo de ensino e aprendizagem (TARDIF M, 2012).

Para que a aprendizagem ocorra a partir da utilização destas ferramentas, é necessária a proposição de novas alternativas no sentido de incluir em sala de aula os alunos com necessidades educacionais especiais, e assim possam desfrutar de momentos de aprendizagem significativa, desenvolvendo ao máximo suas potencialidades (CHACON MM, PEDRO KM, 2013).

O uso dos recursos tecnológicos nos diferentes espaços educacionais não pode ser inserido apenas por imposição cultural-tecnológica, mas sim como suporte, que venham agregar no sentido da construção de uma rede de conhecimentos, onde possa valorizar as diferenças qualitativas, principalmente nas práticas pedagógicas, de maneira que contribua para uma educação mais humana e inclusiva (BARRETO RG, 2003).

Pensar em uma escola inclusiva implica desenvolver uma série de habilidades, dentre elas o planejamento e a utilização de estratégias metodológicas diversificadas, tais como: materiais visuais, softwares didáticos, aplicativos, programas de desenho, o uso do computador e outros (SKLIAR C, 1998). 
Trazendo para o uso dos softwares educativos no processo de desenvolvimento e aprendizagem dos alunos, público alvo da educação especial em que carecem de novas alternativas, somos advertidos de que os instrumentos e os signos proporcionam a mediação que impulsionam o desenvolvimento (VYGOTSKY LS, 1994).

Os softwares educativos se sobressaem como sendo um dos recursos pedagógicos de grande relevância para o ensino e aprendizagem de alunos com deficiência intelectual, pois aguçam a atenção e a concentração, habilidades fundamentais no processo de alfabetização de todo e qualquer educando, podendo promover ainda a inclusão digital e social (BALBINO RR, 2009).

Diante deste processo de construção é de fundamental importância que o educador entenda e visualize o computador como um recurso pedagógico, sendo esse um meio e não um fim em si mesmo, apesar de sua contribuição no sentido de colaborar para uma maior autonomia e desenvolvimento dos alunos. O êxito, na utilização dessa ferramenta só se efetiva quando se tem a constante mediação do professor durante sua aplicabilidade, não podendo deixar de ter o planejamento prévio dos percursos, objetivos e conteúdos a serem desenvolvidos. A partir destas tomadas de decisões, encontrar-se os subsídios fundamentais para a escolha adequada dos softwares que melhor atenderão as necessidades e habilidades dos seus educandos, dinamizando ainda a avaliação destes sujeitos.

A escolha dos softwares educativos como um recurso pedagógico na educação especial, requer do professor uma atenção e planejamento, para que sejam alinhados com os objetivos esperados na aprendizagem. É necessário fazer uma diferenciação dos softwares para os fins de verificação dos conhecimentos prévios bem como para a interação do aluno com o programa de forma que permita a construção do conhecimento (SILVA CMO, 2006).

A utilização das TIC's com mediação é a maneira mais adequada para garantir aos alunos uma aprendizagem significativa. Entretanto, é necessário apontar as teorias pessoais que se sobrepõem em tal escolha, para que o professor possa estabelecer estratégias e selecionar de forma crítica as ferramentas computadorizadas, para que não banalize o seu uso (VIANA PBM, 2006).

\section{RESULTADOS}

Utilizou-se como instrumento para a pesquisa o Software Coelho Sabido, um recurso pedagógico com ambientes lúdicos, dinâmicos e interativos. Através do jogo o aluno é motivado a avançar diferentes fases superando suas limitações brincando.

É válido considerar que cada aluno reage de maneira ímpar, cabendo ao educador, estar atento a singularidade de cada sujeito, levando em consideração seus conhecimentos prévios necessidades, interesses e que apesar das dificuldades, o aluno com deficiência intelectual tem potencialidades que precisam ser reconhecidas e valorizadas. Os momentos de condução para novas aprendizagens no decorrer do jogo, exigiu a mediação constante do professor. A qualidade dessa mediação e a credibilidade depositada nas habilidades reais do aluno foram fatores determinantes para o alcance dos objetivos estabelecidos para o jogo.

O software selecionado com os seus respectivos ambientes, foi bastante expressivo no contexto da aprendizagem, considerando que nos ambientes oferecidos eram ricos os recursos no sentido de identificar números associando-os as suas quantidades; fazer relação entre maior e menor; desenvolver o raciocínio lógico matemático; aprender a contar e a somar; identificar letras sílabas e palavras; reconhecer letras maiúsculas e minúsculas; desenvolver a consciência fonológica; ampliar o vocabulário; trabalhar habilidades para a introdução a leitura. Com intervenção foi capaz de organizar objetos a partir de critérios de associações de imagens, cores, sons e tamanhos.

Fica explícita a ajuda que as atividades realizadas com uso do software educativo proporcionaram ao aluno, no tocante a aprendizagens ligadas a linguagem e conceitos matemáticos, bem como os aprimoramentos de habilidades e potencialidades para a motivação, percepção audiovisual, superação, 
resolução de problemas autonomia e manutenção dos focos de atenção aliados à ludicidade. Houve situações em que necessitou do apoio de materiais concretos e da mediação sistemática do professor para que pudesse atingir os objetivos propostos (Tabela 1).

Jogo "parque de diversões".

Tabela 1 - Ambientes para intervenção e intencionalidades.

\begin{tabular}{|c|c|}
\hline \multicolumn{2}{|r|}{ COELHO SABIDO PARQUE DE DIVERSÕES } \\
\hline AMBIENTES DO JOGO & $\begin{array}{c}\text { INTENCIONALIDADE } \\
\text { - Identificar números associando-os as suas quantidades; }\end{array}$ \\
\hline 1- Clube dos números & $\begin{array}{l}\text { - Desenvolver o raciocínio logico matemático; } \\
\text { - } \quad \text { Aprender a contar e a somar. } \\
\text { - } \quad \text { Recontificar letras sílabas e palavras; } \\
\text { - Recer letras maiúsculas e minúsculas; }\end{array}$ \\
\hline 2- ABC Lanches & $\begin{array}{l}\text { - Desenvolver sua consciência fonológica; } \\
\text { - } \quad \text { Ampliar o seu vocabulário; } \\
\text { - Trabalhar habilidade para a introdução a leitura. }\end{array}$ \\
\hline 3- Cabana das formas & $\begin{array}{l}\text { - Organizar objetos obedecendo a critérios: forma geométrica, } \\
\text { - Aom e cor; } \\
\text { - Aprimorando habilidades áudio visuais. }\end{array}$ \\
\hline 4- Bandinha dos conjuntos & - Trabalhar associações de cor, som e tamanho. \\
\hline
\end{tabular}

\section{Clube dos números}

No ambiente clube dos números o jogador irá interagir com a personagem Malú uma gata que faz contas. Ela irá organizar a brincadeira de esconde-esconde. Dentro dos troncos das árvores estão escondidas várias espécies de animais que vivem na floresta. $O$ jogador tem a missão de encontrar a quantidade indicada por Malu fazendo a relação entre número e quantidade. No Clube dos Números, o prêmio a ser conquistado é um carrinho "bate-bate".

Inicialmente o estudante explorou com autonomia os ambientes do jogo, sem a preocupação de compreender os objetivos. Através de comandos de voz recebia dicas de como entrar no clube. Os recursos audiovisuais despertaram momentos de atenção e alerta. O aluno revelou dificuldades para o reconhecimento visual dos números e fazer a relação entre número e quantidade.

Com mediação foi adquirindo melhores resultados. Os acertos levavam o aluno a assumir uma postura positiva diante do jogo. O lúdico foi um fator positivo, pois o aluno demonstrou desejo em prosseguir mesmo diante de suas limitações para a abstração e desenvolvimento da memória. Brincando ele pode aprimorar conceitos matemáticas, resolvendo os desafios propostos pelo jogo.

\section{$A B C$ lanches}

No ambiente do $A B C$ Lanche o jogador interage com o personagem Bento, um cão mestre cuca e o seu Garção o Coelho Sabido. O jogador tem que ajudar a atender aos pedidos de Lanches. Bento faz a leitura dos pedidos e o jogador tem que encontrar a porta onde estão guardados os ingredientes, identificadas pela letra inicial. A cada acerto o nome dos ingredientes vão compondo uma lista que aparece abaixo da esteira. Ele terá que conquistar quatro bilhetes para obter uma nova montanha russa.

Os recursos auditivos foram decisivos para a interação do aluno com o jogo. Demonstrou habilidades para manusear os componentes periféricos (teclado e mouse). Explorou o cenário de abertura com autonomia e curiosidade. Necessitou de mediação para compreender os objetivos propostos. 
O aluno apresentou melhores resultados com as letras maiúsculas. O aluno teria que identificar qual a porta onde estava guardado o alimento através do reconhecimento da letra inicial. Ao possibilitar a interação sem mediação, clicava nas portas aleatoriamente. Diante dos erros pedia ajuda. Foi necessário utilizar o alfabeto móvel como recurso reforçador. A partir da percepção visual o aluno atingiu melhores resultados para identificar as letras. Com mediação visual e auditiva conseguiu interagir melhor com o jogo.

\section{Cabana de formas}

$\mathrm{Na}$ Cabana das formas o jogador interage com o personagem do macaco Piteco. Nesta atividade o desafio é organizar objetos numa caixa de brinquedos, obedecendo os critérios como: forma geométrica, semelhança nas imagens, som e cor. Após concluir esta sessão o jogador recebe os bilhetes para montar uma nova roda gigante. Desfrutou de cenários coloridos, lúdicos e dinâmicos com animações que davam vida e movimento, e despertavam sua atenção. Batia palmas tentando acompanhar o ritmo da música. O jogo possibilitou o desenvolvimento de habilidades de organização de imagens por categoria (cores, formas e imagens), trabalhando de forma lúdica a percepção visual e espacial.

Os recursos audiovisuais disponíveis foi um dos pontos fortes para a manutenção do foco de atenção do aluno. Apresentou maior compreensão na seriação de imagens de animais e dificuldade para organização de objetos a partir dos conceitos de igualdade de cores e formas geométricas, dando-nos pistas de que suas limitações se centram na possibilidade de abstração.

Diante dos erros ficava mais agitado e com palavras tentava expressar seus sentimentos. Nestes momentos desviava o foco com mais frequência, apresentado desmotivação para continuar. Precisava da mediação do professor para rever seu foco, além de estímulos para sua autoestima.

\section{Bandinha dos conjuntos}

Neste ambiente o jogador tem que seguir as pistas de voz do Formigão, o Líder da banda. O aluno desenvolve habilidades para a associação por cores, sons e tamanhos, desenvolvendo a memória e a percepção auditiva e visual. Ao fim de cada sequência recebe um bilhete, que somado a quantidade de quatro fichas recebe como recompensa uma nova xícara voadora.

Promoveu aprendizagens significativas no reconhecimento de cores, tamanhos e imagens a partir da percepção visual e auditiva. Estimulou o desenvolvimento de novos esquemas de conhecimento alicerçados em habilidades de observação, identificação, comparação e classificação. $O$ aluno vivenciou situações de autonomia que favoreceram sua interação com o jogo.

O lúdico assumiu importante papel motivador. Foi possível perceber que a musicalidade foi um dos fatores que despertou no aluno o desejo em prosseguir. Apresentou dificuldades para seriação dos componentes da banda atendendo aos conceitos de tamanhos (baixo/alto). Para formar categorias a partir de cores e instrumentos musicais, revelou maior autonomia. Para reforçar o reconhecimento de cores, foi necessário utilizar material concreto.

\section{CONCLUSÃO}

As tecnologias computacionais aqui mencionadas através do uso do software educativo "Coelho Sabido" representaram um grande potencial mediador para o desenvolvimento de habilidades ligadas à coordenação motora, percepção auditiva e visual, habilidades para a atenção, memória, concentração, autonomia, raciocínio lógico e da capacidade para resolver problemas. As experiências proporcionadas pelos ambientes do jogo conduziram o aluno a aprendizagens significativas formando pares de números, letras, silabas e palavras, formas geométricas e cores, bem como o desenvolvimento de conceitos matemáticos sobre número e quantidade e a lateralidade (esquerda/direita, longe/perto, abaixo/acima). Destacou-se ainda a importância da mediação do professor durante o processo de interação do aluno com o jogo. Esse entendimento é corroborado pelo que afirma Vygotsky, em seu estudo sobre a Zona de Desenvolvimento Proximal (ZDP), em que a aprendizagem e o desenvolvimento acontecem a partir das relações e mediações do indivíduo com seu ambiente sociocultural. 


\section{REFERÊNCIAS}

1- ALENCAR GAR et al. Atendimento educacional especializado. In: Apostila do curso de especialização em Atendimento Educacional Especializado. Universidade Estadual de Maringá (UEM), 2010, 39p.

2- BALBINO RR. et. al. Jogos educativos como objetos de aprendizagem para pessoas com necessidades educacionais especiais. Revista Novas Tecnologias na Educação. Rio Grande do Sul, 2009; 7 (3): 1-13.

3- BARRETO RG. Tecnologias na formação de professores: o discurso do MEC. Revista Educação e Pesquisa. São Paulo, 2003; 29(2): 271-286.

4- BATISTA CAM, MONTOAN MTE. Atendimento educacional especializado em deficiência mental. In: GOMES, Adriana L. Limaverde et al. Formação continuada a distância de professores para o atendimento especializado: deficiência mental. Brasília: SEESP/SEED/MEC, 2007, 83p.

5- BRASIL. Ministério da Educação. Secretaria de Educação Especial. Política nacional de educação especial na perspectiva da educação inclusiva. Brasília: MEC/SEESP, 2008, 19p.

6- CHACON MM, PEDRO KM. Softwares educativos para alunos com deficiência intelectual: estratégias utilizadas. Biennale internationale de l'éducation. 2013; 1-14.

7- MANTOAN MTE. Inclusão escolar: o que é? Por quê? Como fazer?. São Paulo: Moderna, 2003. (Col. Cotidiano Escolar), 51p.

8- SANCHO JM. (org.). Para uma tecnologia educacional. 2. ed. Porto Alegre: Artmed, 2001, 327p.

9- SILVA, OM. Epopeia ignorada. Edição de Mídia. São Paulo: Editora Faster, 2009, 470p.

10- SILVA CMO. Criança-professor-computador: possibilidades interativas e sociais na sala de aula. Revista de Humanidades. Fortaleza, 2006; 21(2): 151-136.

11- SKLIAR C. A surdez: um olhar sobre as diferenças. Porto Alegre: Dimensão, 1998, 192p.

12- TARDIF M. Saberes docentes e formação profissional. 13. ed. Petrópolis, RJ: Vozes, 2012, 317p.

13- VIANNA PBM. Formação de professores mediadores para o uso das TIC: elementos teóricos e práticos trabalhados em uma pesquisa-ação. UNIRevista. São Leopoldo, 2006; 1(2): 1-12.

14- VOLTOLINI R. O discurso do capitalista, a psicanálise e a educação. In: LEITE, NVA.; AIRES, S.; VERAS, V. (Org.). Linguagem e gozo. Campinas: Mercado das Letras, 2007, 15p.

15- VYGOTSKY LS. A formação social da mente: o desenvolvimento dos processos psicológicos superiores. 5 ed. São Paulo: Martins Fontes, 1994, 90p.

16- Obras Escogidas: fundamentos de defectologia, v. 5. Madrid: Visor, 1997, 400p.

17- Pensamento e linguagem. Tradução Jefferson Luiz Camargo. 3. ed. São Paulo: Martins Fontes, 2005, 159p. 